\title{
A STUDY OF THE EFFECTS OF HEMORRHAGE, TRAUMA, HISTAMINE AND SPINAL ANESTHESIA ON THE COMPOSITION OF THE BLOOD WHEN NO FLUIDS ARE INJECTED AND WHEN FLUIDS ARE INTRODUCED INTRAVENOUSLY
}

\author{
By J. W. BEARD, HARWELL WILSON, B. M. WEINSTEIN, AND \\ ALFRED BLALOCK \\ (From the Department of Surgery, Vanderbilt University, Nashoille)
}

(Received for publication September 3, 1931)

In previous studies $(1,2)$ the composition of the blood has been determined before, during and after the injection of various fluids intravenously under normal and abnormal conditions. The abnormal conditions consisted of some experiments in which a decline in blood pressure was produced by trauma to the intestines and others in which probably due either to the anesthetic or to the fluid that was injected intravenously there was an early marked decline in the pressure. The results of these experiments led us to further studies on the composition of the blood of animals in which a decline in pressure was produced by other methods. These methods consisted of (1) graded hemorrhages, (2) trauma to an extremity, (3) the subcutaneous injection of histamine and (4) spinal anesthesia. These procedures were chosen because a large number of the instances of low blood pressures in patients are due to similar causes. Experiments were performed both with and without the introduction of fluids intravenously. The fluids that were chosen for study were normal salt solution and Evans' gum acacia-glucose-saline solution. These two fluids together with others were employed in the previous studies and in the present experiments they were used as examples of solutions of crystalloids and of colloids.

\section{METHODS AND RESULTS}

The experimental animals in all instances were dogs. They were anesthetized by morphine except in the experiments in which an extremity was traumatized. In the latter experiments, sodium barbital, 0.3 gram per kilogram of body weight, was administered intravenously. The animals gave no evidence of pain and were killed at the completion of the experiments. A cannula that was connected to a mercury manometer was placed in the carotid artery for the blood pressure determinations. Samples of blood for the various analyses were obtained from the femoral vein. The blood that was removed was replaced by an equal volume. 
At the beginning of all experiments, specimens of blood were removed for determinations of the hemoglobin, the hematocrit, the blood volume, the total protein, albumin and globulin. These studies, except for those on the blood volume, were repeated after intervals of one, two and one-half, four, five and one-half and seven hours. Van Allen tubes were used for the hematocrit determinations. The method of Cohen and Smith (3) was employed in determining the percentage of hemoglobin. Vital red was used in the estimation of the control blood volume. These figures are placed in brackets in the tables. The changes in the blood volume during the course of the experiments were assumed to vary in an inverse ratio to the alterations in the percentage of hemoglobin. The hematocrit readings were used in calculating the volume of red blood cells and plasma. The nitrogen determinations on blood serum and urine were performed by the Kjeldahl-Gunning method. In the tables, nitrogen is expressed as protein. The absolute or entire amounts of total protein, albumin and globulin were obtained by multiplying the percentage of each by the volume of plasma.

A decline in blood pressure was produced by four different methods and for descriptive purposes the experiments are divided into four groups. In each group, studies were first performed on the effects of the procedure when no fluid was introduced intravenously. In subsequent studies, fluids were injected at a constant rate during the first four hours of the experiments. The volume of fluid introduced equalled $10 \mathrm{cc}$. per kilogram of body weight per hour. The fluids injected in the different experiments were normal salt solution and Evans' solution of 6.0 per cent gum acacia and 20 per cent glucose in normal saline. In addition in the experiments on histamine, the effects of injecting blood serum were studied also.

The results of all experiments are summarized in the text. Due to lack of space, the results of only one experiment are given in detail in the tables.

\section{EXPERIMENTS ON THE EFFECTS OF GRADED HEMORRHAGE}

The entire amount of blood that was withdrawn equalled 4.0 per cent of the body weight. Its removal was distributed as follows. After the control determinations had been performed, a volume of blood equal to 1.0 per cent of the body weight was removed. One hour later and two and one-half hours later just prior to the withdrawal of samples for the analyses, blood equalling 1.5 per cent of the body weight was removed.

Since blood was withdrawn from the circulation, the calculations were somewhat different from those in most of the other experiments. After calculating the alterations in the blood volume from the original by the use of the hemoglobin and hematocrit determinations, deduction was made for the amount of blood that had been removed. The absolute 
amount of plasma protein was obtained by multiplying the volume of plasma by the percentage of protein. The sum of this figure and the amount of protein that was present in the blood that was removed is placed in parentheses in the tables.

\section{A. The effects of graded hemorrhages alone on the composition of the blood}

Three experiments were performed in which the effects of graded hemorrhage were studied. No fluid was introduced. In two of the experiments, there was a large decline in the arterial pressure. The alterations in the hemoglobin and hematocrit readings were very small and inconstant. There were decreases in the volumes of whole blood, of plasma and of red blood cells. The percentages of total protein, of albumin and of globulin decreased very slightly. The absolute amounts of the protein constituents in the blood plasma decreased. However, if one includes in these figures the amount of protein that was present in the withdrawn blood, it is to be seen in one experiment that there was an increase in the absolute amount of protein constituents, in another there was no alteration and in the third there was a slight decrease. The results of one of these experiments are given in Table $I$.

\section{B. The effects of graded hemorrhages and of the intravenous injection of normal salt solution on the composition of the blood}

Three such experiments were performed. In two of the three experiments there was a marked decline in the blood pressure. There was a decrease in the hemoglobin and hematocrit readings in all experiments. The volume of plasma declined rather markedly in two of the three experiments. A reduction of the percentages of total protein, albumin and globulin in the blood serum was found. The absolute amounts of the protein constituents in the blood plasma decreased. However, if one adds to that in the blood stream the protein that was present in the blood that was withdrawn, it is to be seen in two of the experiments that there was an increase in the absolute protein. The results of one of these experiments are to be found in Table I.

\section{The effects of graded hemorrhages and of the intravenous injection of gum acacia-glucose-saline solution on the composition of the blood}

Only one experiment of this type was performed. The blood pressure did not decline until after the injection of fluid was stopped. There was a decrease in the percentage of hemoglobin and in the hematocrit readings. The volume of plasma increased during the injection of the fluid and returned later to the original level. There was a marked decrease in the percentages of total protein, albumin and globulin. The absolute amounts of the protein constituents in the blood plasma decreased. The sum of the protein that remained in the plasma of the 


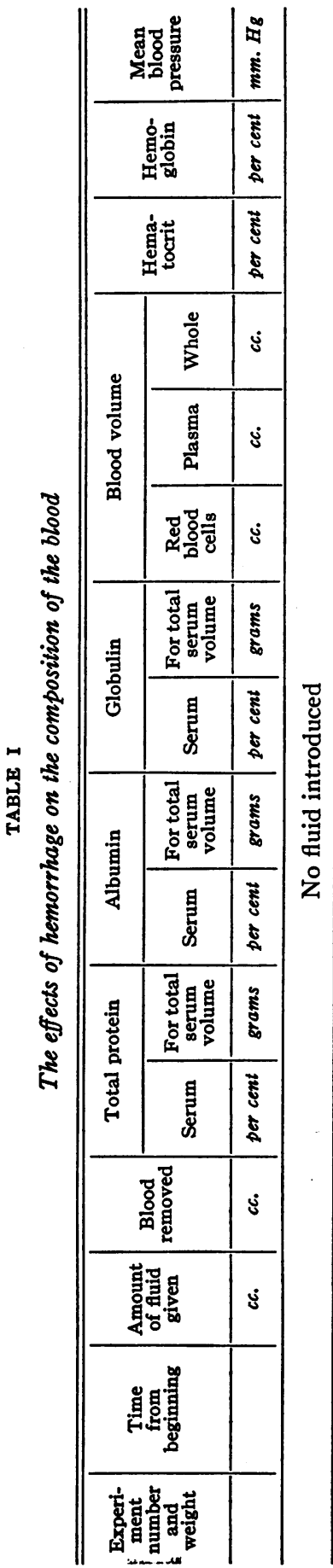

\begin{tabular}{|c|c|}
\hline$\stackrel{\infty}{=}$ & 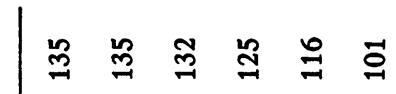 \\
\hline ஊ & 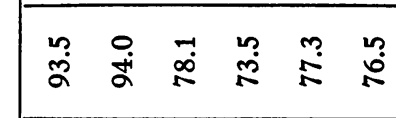 \\
\hline 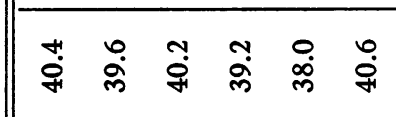 & 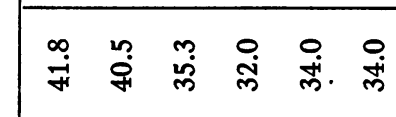 \\
\hline 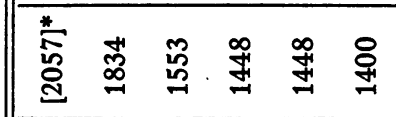 & 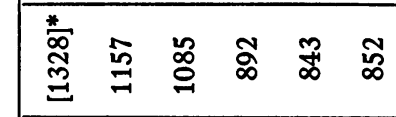 \\
\hline 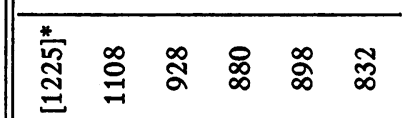 & 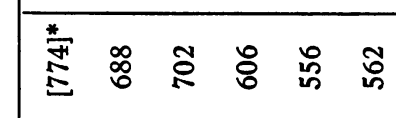 \\
\hline 莕 & 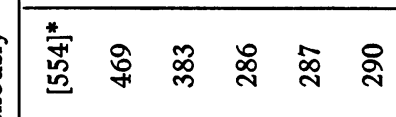 \\
\hline 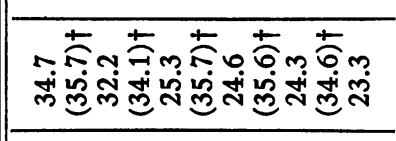 & 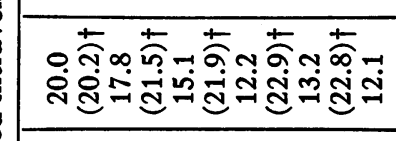 \\
\hline œ & 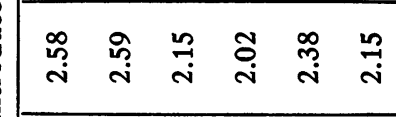 \\
\hline 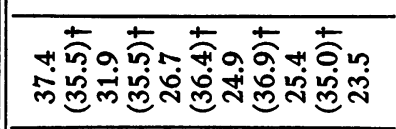 & 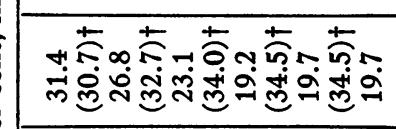 \\
\hline 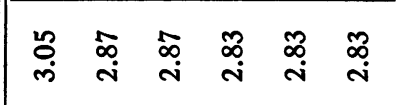 & 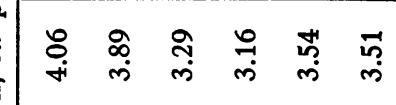 \\
\hline 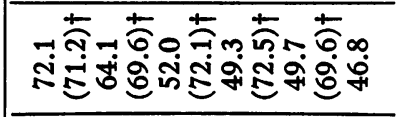 & 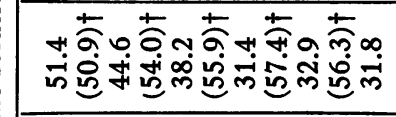 \\
\hline 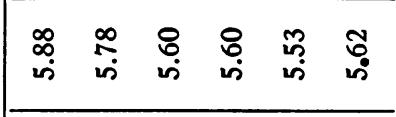 & 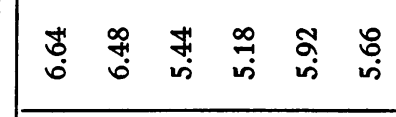 \\
\hline 용 용 号 & ○䓵序品 \\
\hline & ○ 莫 学品 \\
\hline 要 & 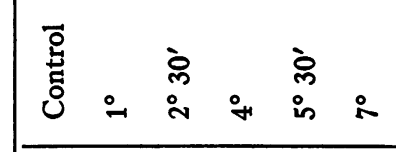 \\
\hline 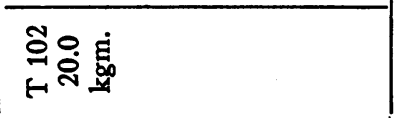 & 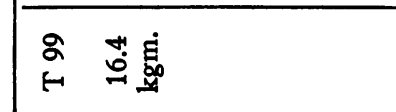 \\
\hline
\end{tabular}


J. W. BEARD, H. WILSON, B. M. WEINSTEIN, AND A. BLALOCK 295

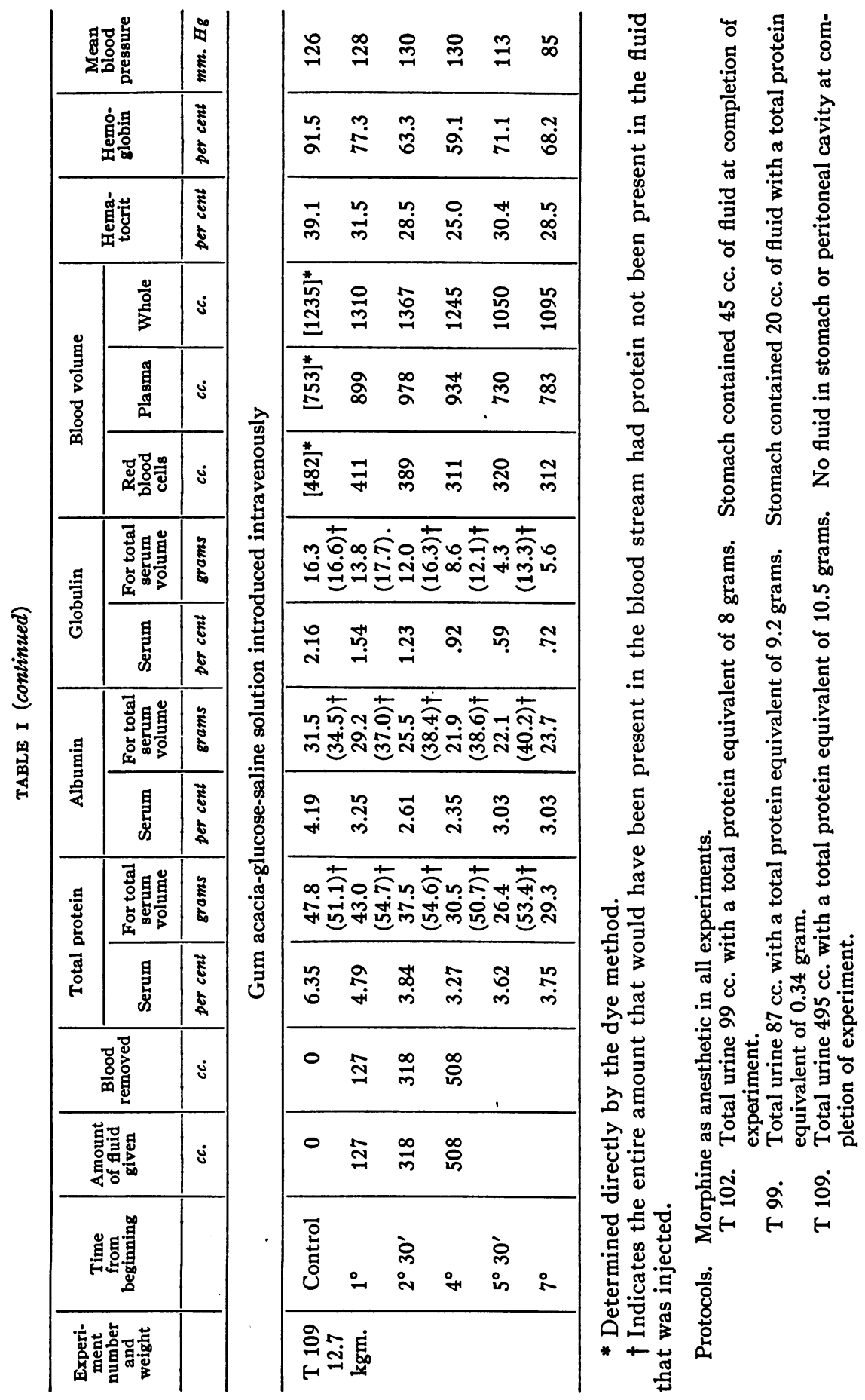


blood stream and that removed gave a figure in excess of that obtained during the control period. The results of this experiment are given in Table I.

\section{EXPERIMENTS ON THE EFFECTS OF TRAUMA TO AN EXTREMITY}

As has been stated, the animals were deeply anesthetized by sodium barbital. After the control determinations had been performed, one of the posterior extremities was traumatized by striking it with a hammer. In some instances, slight additional trauma was subsequently necessary since the blood pressure did not decline sufficiently as a result of the initial injury. At the completion of the experiments, the posterior portion of the body was divided into two parts by a method previously described (4). The difference in the weights of the two parts was considered a measure of the fluid that was lost from the blood stream into the injured area.

The various determinations were performed in these experiments as in all others that are reported in this paper. However, due to the fact that the amount of blood that was lost into the injured area could not be determined during the course of the experiments, some of the calculations were impossible. An attempt was made to calculate the blood volume and the absolute amounts of the protein constituents at the termination of the experiments. It is realized that the method employed is not in any sense absolute. As usual, the control blood volume and the alterations in the hematocrit and hemoglobin readings were used in computing the changes in the volumes of red blood cells, plasma and whole blood. From the blood volume thus obtained, the amount of fluid that was lost into the injured area as determined by the amputations was subtracted and the result was considered as the blood volume at the end of the experiment. The fluid that was lost into the extremity was considered as having an hematocrit which was the average of all those obtained on the venous blood throughout the experiment. With this assumption the volumes of red blood cells and of plasma in the injured area were calculated. These figures were subtracted from the volumes of red blood cells and of plasma which presumably would have been present in the blood stream had not the loss occurred.

\section{A. The effects of trauma to an extremity on the composition of the blood}

Two experiments on the effects of trauma to an extremity were performed. The arterial pressure declined markedly in both experiments. There was an increase in the hematocrit and hemoglobin readings. The volumes of whole blood, plasma and red blood cells decreased. The content of the serum in total protein, albumin and globulin was not altered significantly during the experiments. The absolute amount of the protein constituents was greatly diminished. The results of one of these experiments are given in Table II. 
J. W. BEARD, H. WILSON, B. M. WEINSTEIN, AND A. BLALOCK 297

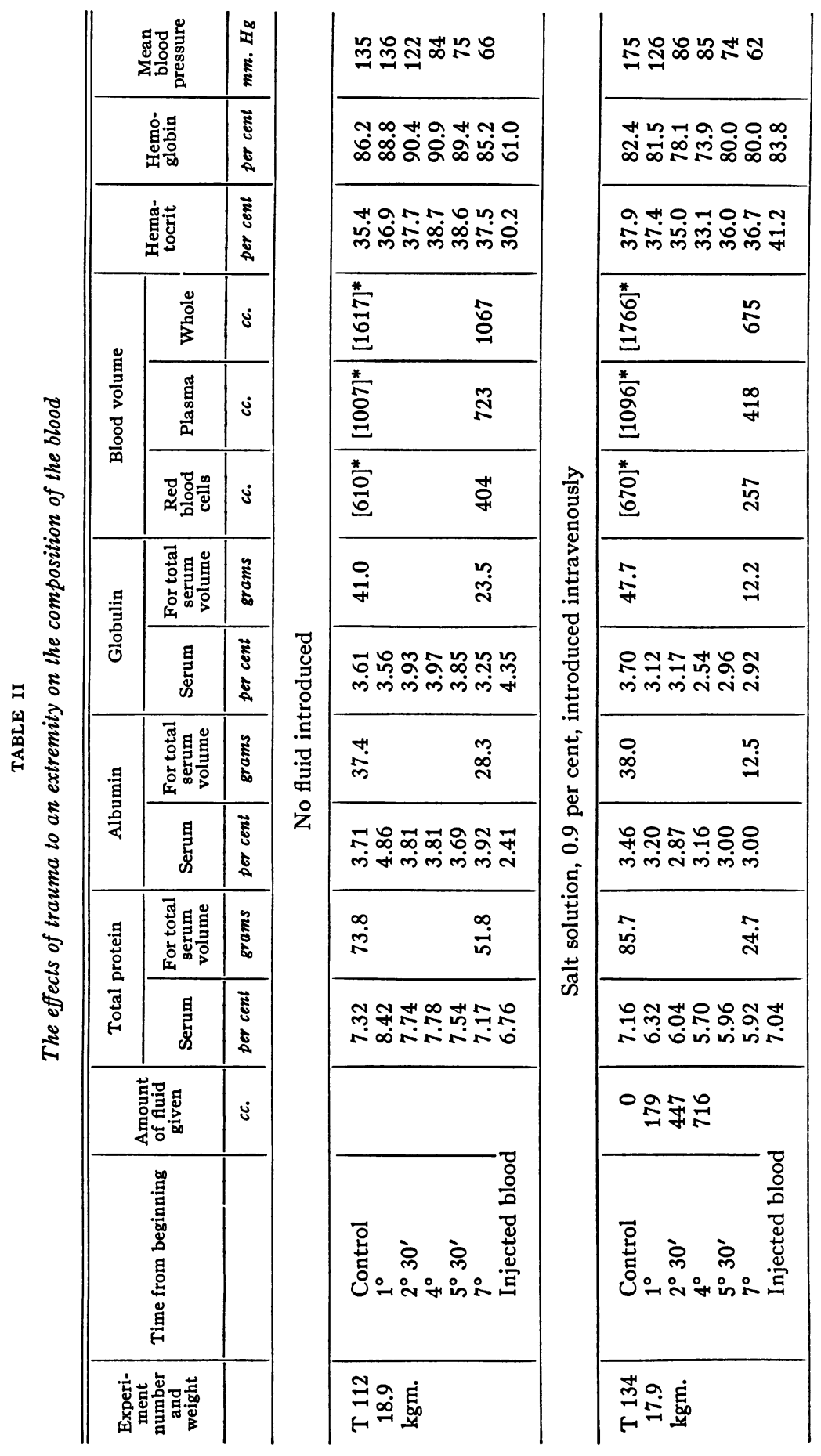




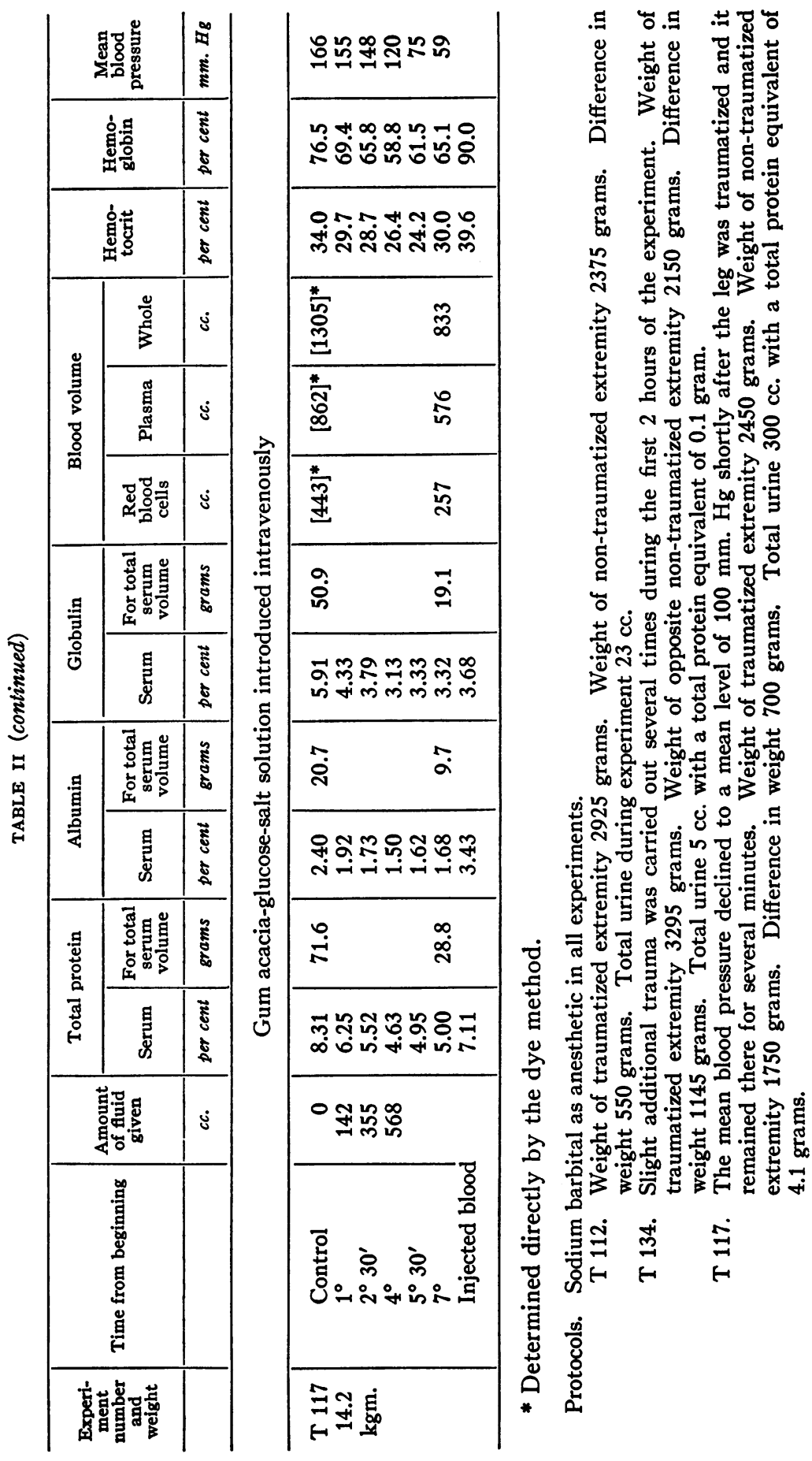


J. W. BEARD, H. WILSON, B. M. WEINSTEIN, AND A. BLALOCK 299

B. The effects of trauma to an extremity and of the intravenous injection of normal salt solution on the composition of the blood

Three experiments of this type were performed. A greater amount of trauma was necessary for the production of a low blood pressure than in the experiments in which no fluid was injected. In two of the present experiments, the blood pressure did not reach a low level until after the introduction of fluid had been terminated. The alterations in the hemoglobin and hematocrit readings were small and variable. The volume of blood plasma decreased markedly. There were small but definite decreases in the percentages of total protein, albumin and globulin in the blood serum. The absolute amounts of the protein constituents decreased markedly. The results of one of these experiments are contained in Table II.

C. The effects of trauma to an extremity and of the intravenous injection of gum acacia-glucose-saline solution on the composition of the blood

Two experiments of this type were performed. The blood pressure declined during the administration of fluid but did not reach a low level until after the injection was stopped. There was a marked decrease in the hemoglobin and hematocrit readings. The calculated volume of plasma increased in one experiment and decreased in the other. There were marked decreases in the percentages of total protein, albumin and globulin in the blood serum. The absolute amounts of the protein constituents decreased. The results of one of these experiments are to be found in Table II.

\section{EXPERIMENTS ON THE EFFECTS OF HISTAMINE}

The histamine solution that was injected subcutaneously contained one milligram of the drug per cubic centimeter of salt solution. It was given in sufficient amounts to maintain the blood pressure definitely depressed during the first four hours of the experiments.

\section{A. The effects of the subcutaneous injection of histamine on the composition of the blood}

Three experiments were performed in which the effects of the subcutaneous injection of histamine were studied. The blood pressure rose following the completion of the injections but did not return to the previous control level. The concentration of the red blood cells and the percentage of hemoglobin increased in all experiments. The volume of blood plasma diminished. There was a slight increase in the percentages of total protein, albumin and globulin in the blood serum. The absolute amounts of the protein constituents in the blood plasma decreased. The results of one of these experiments are given in Table III. 


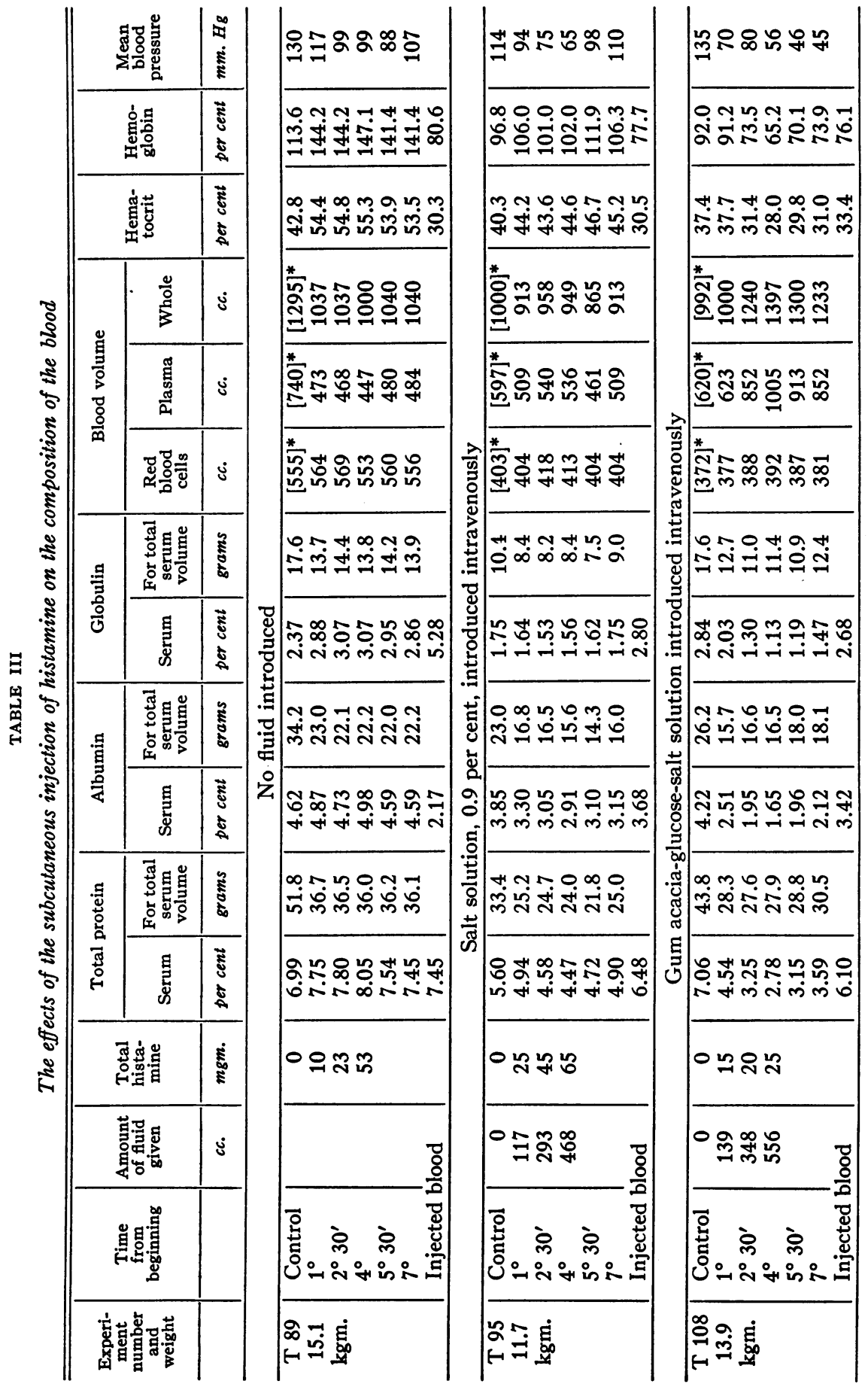


J. W. BEARD, H. WILSON, B. M. WEINSTEIN, AND A. BLALOCK 301

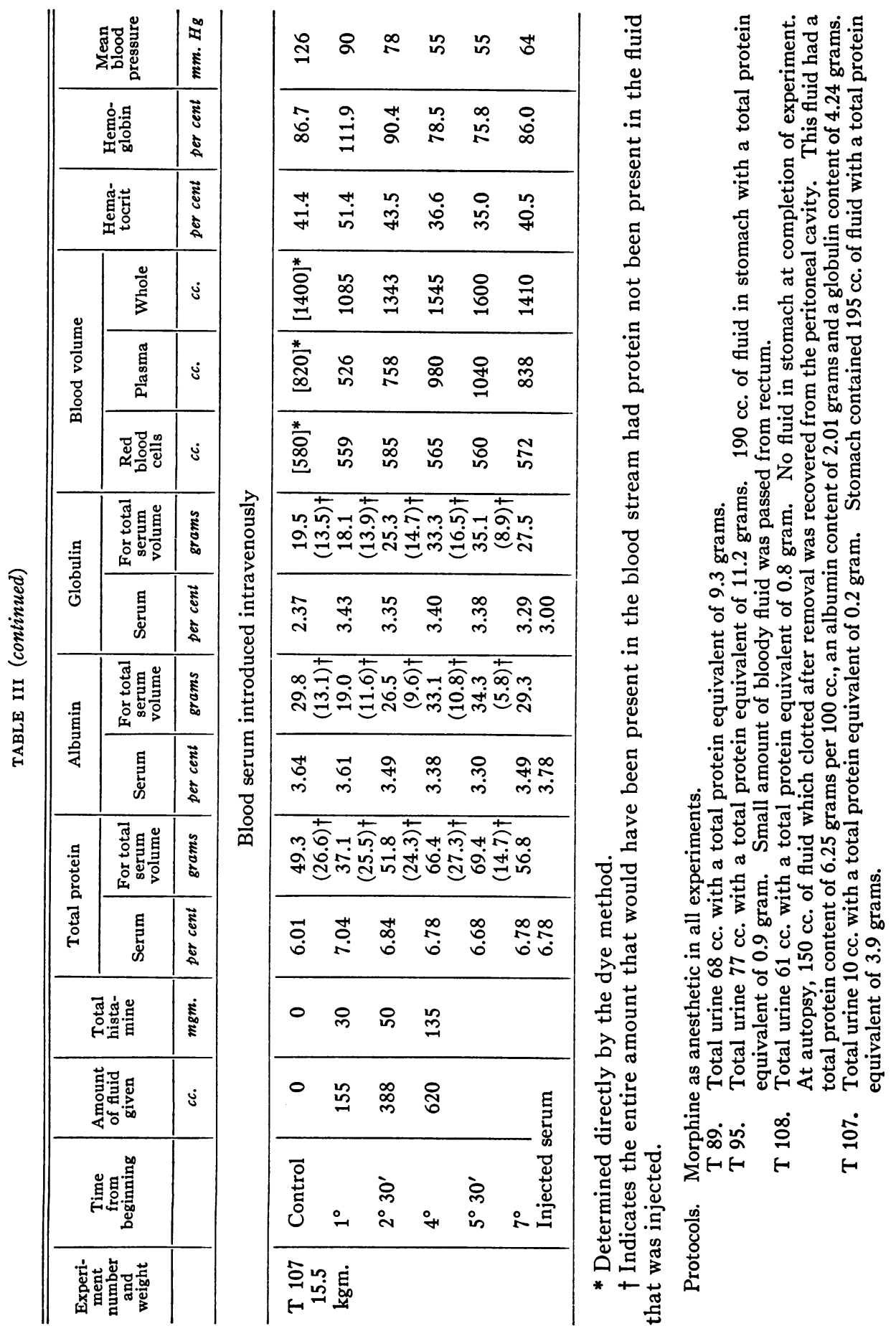




\section{B. The effects of the subcutaneous injection of histamine and of the intravenous injection of normal salt solution on the composition of the blood}

Three experiments of this type were performed. A marked decline in the blood pressure was produced in all of them. There was a definite but not great increase in the hematocrit and hemoglobin readings in two of the experiments. In the remaining experiment, there was a slight decline. The volume of blood plasma decreased in two experiments and increased slightly in one. There was a decrease in the percentage of the protein constituents of the serum in all experiments. In none of these was the decrease very great. The absolute amounts of the protein constituents decreased in two experiments and remained at approximately the control level in the other one. At the completion of each of the experiments, the stomach contained a large amount of fluid. The results of one of these experiments are to be found in Table III.

\section{The effects of the subcutaneous injection of histamine and of the intravenous injection of gum acacia-glucose-saline solution on the composition of the blood}

Two experiments were performed. A marked decline in the blood pressure was produced in both. After a slight initial increase, there was a great decrease in the hemoglobin and hematocrit readings. The volume of blood plasma increased. There was a great decrease in the percentages of total protein, albumin and globulin in the blood serum. The absolute amounts of the protein constituents decreased. The results of one of these experiments are given in Table III.

\section{The effects of the subcutaneous injection of histamine and of the intravenous injection of blood serum on the composition of the blood}

Two experiments were performed in which the effects of the injection of histamine and of blood serum were studied. The serum was obtained from a normal dog the blood of which was not incompatible with that of the experimental animal. A marked decline in the blood pressure followed the injection of histamine in each experiment. There was an increase in the hemoglobin and hematocrit determinations during the early part of the experiments and a decrease later. The volume of blood plasma first decreased slightly and then increased. There was an increase in the percentages of total protein and globulin in the blood serum, except for an initial decrease in one experiment. The absolute amounts of the protein constituents in the blood plasma increased greatly. However, if one corrects for the protein that was present in the injected serum, a decrease in the absolute amount of plasma protein is found. The latter figures are placed in brackets in the table. The results of one of these experiments are to be seen in Table III. 


\section{EXPERIMENTS ON THE EFFECTS OF SPINAL ANESTHESIA}

A five per cent solution of procaine hydrochloride was used as the spinal anesthetic. With the animal lying on its side, the fluid was introduced into the canal in the lumbar region. Small amounts of the procaine were injected frequently until a marked decline in the blood pressure resulted. The animal was then placed on its back.

\section{A. The effects of spinal anesthesia alone on the composition of the blood}

Four experiments are reported in which the effects of spinal anesthesia were studied. In several others, either no significant decline in pressure was produced or death followed shortly after the injection of the procaine. The concentration of the blood and the percentage of hemoglobin increased in three of the four experiments but in no instance was the increase very great. In three of the experiments, there was a slight decrease in the volume of plasma. However, in two of these, the decline did not appear during the first hour of the experiment when the blood pressure was lowest. The percentages of the protein constituents in the blood serum remained practically unaltered during the experiments. In two of the experiments, the absolute amount of plasma protein remained at approximately the control level. In the remaining two, there was no alteration during the first hour, and following this there was a decline. The results of one of these experiments are given in Table IV.

\section{B. The effects of spinal anesthesia and of the intravenous injection of normal salt solution on the composition of the blood}

Two experiments of this type were performed. A marked decline in the blood pressure was produced in each. At the end of the first hour, there was a slight decrease in the hemoglobin and hematocrit readings in each. Following this, they rose to levels a little higher than those observed during the control periods. The plasma volume first increased and then decreased slightly. There were small decreases in the percentages of total protein, albumin and globulin in the blood serum. The absolute amounts of the protein constituents declined but not to a great extent. The results of one of these experiments are contained in Table IV.

\section{The effects of spinal anesthesia and of the intravenous injection of gum acacia-glucose-saline solution on the composition of the blood}

Two experiments were performed. In one of these, the blood pressure remained markedly depressed, while in the other it returned to the control level and remained there several hours. In one experiment the concentration of the red blood cells decreased during the injection of the fluid, and in the other the initial increase in the concentration was followed by dilution. The hematocrit and hemoglobin readings increased following the termination of the injections. There was a decrease in the percent- 


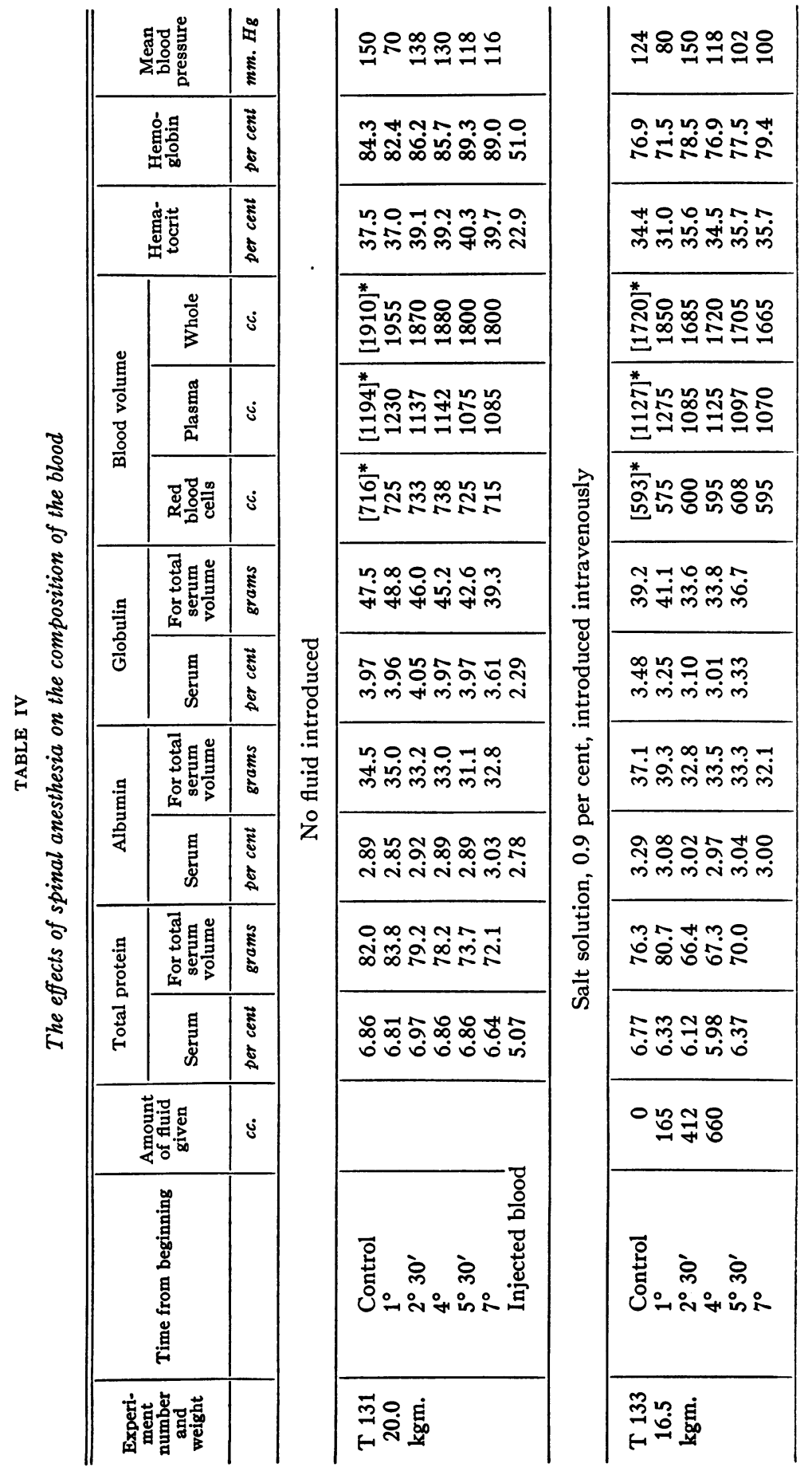


J. W. BEARD, H. WILSON, B. M. WEINSTEIN, AND A. BLALOCK 305

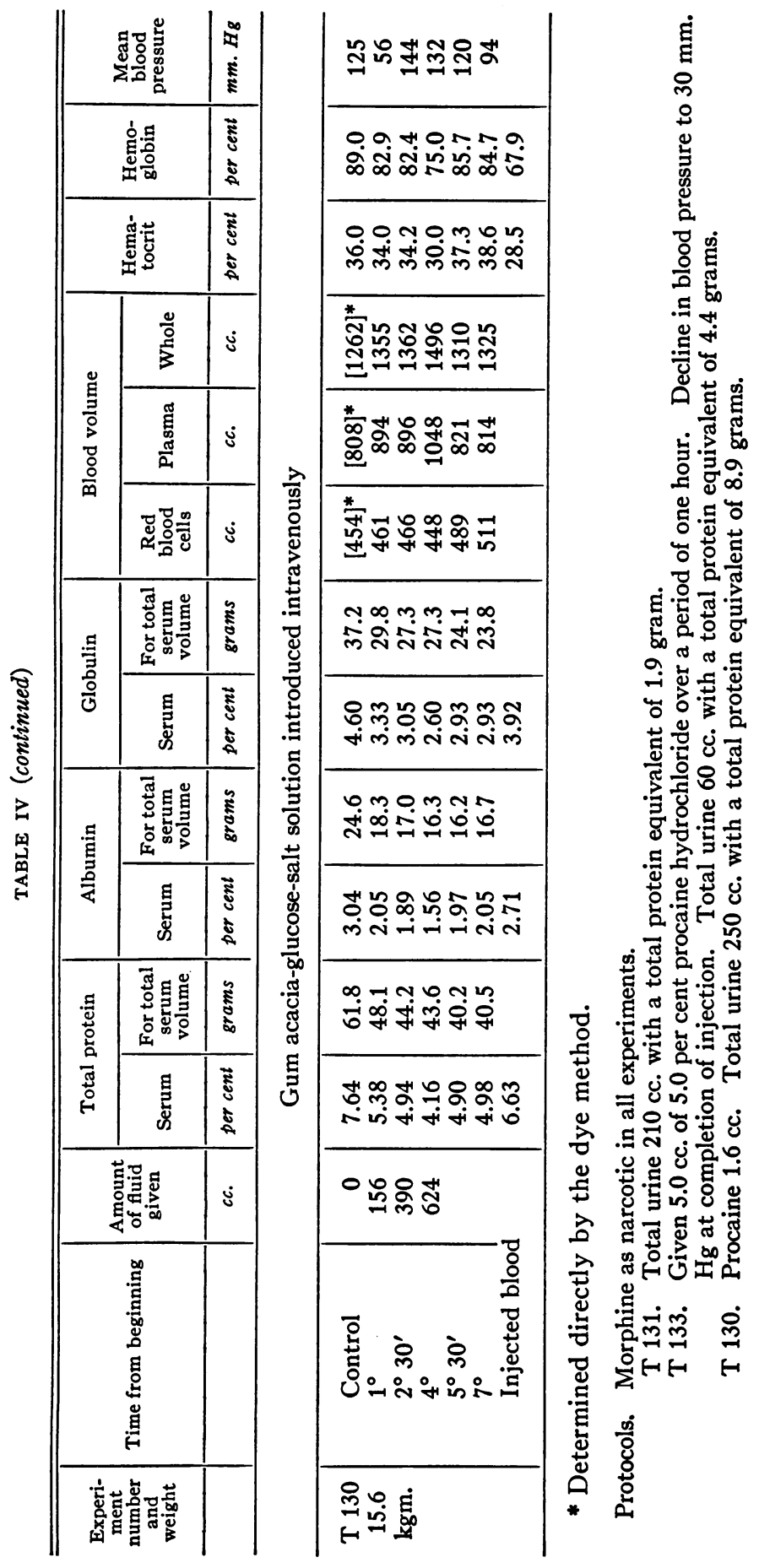


ages of the total protein, albumin and globulin in the blood serum. The absolute amounts of the protein constituents in the blood plasma decreased. The results of one of these experiments are given in Table IV.

\section{DISCUSSION}

In a previous paper (2) experiments were reported in which the cause for the decline in blood pressure was not clearly understood, and in which the injection of fluids intravenously was usually associated with marked decreases in both the percentage and absolute amount of plasma protein. In view of these findings it seemed important to determine whether or not a decline in blood pressure produced in other ways would be associated with similar alterations. For example, if the intravenous injection of salt solution following a severe hemorrhage were associated with a marked decrease in the percentage and absolute amount of protein in the blood serum, its use might be harmful rather than beneficial. The four methods by which the decline in pressure was produced were arbitrarily chosen as being fairly representative of the different ways of causing such a condition.

The findings in the experiments on the effects of hemorrhage were quite different from those previously reported (2) in which the unexplained early decline in the pressure took place. When normal salt solution was injected into the animals from which blood was being removed, a decrease rather than an increase in the concentration of the red blood cells was found. The percentage of protein in the serum decreased but when the protein that was removed was added to that remaining in the blood stream, it was found that the absolute amount of plasma protein usually increased. Calculated in this manner, the increase in one experiment was five grams and in another six grams. In the experiments on hemorrhage the blood pressure readings as listed in the tables are not in all instances very low but they are somewhat misleading in this respect in that the pressure that existed just before the removal of the blood was the one used. During and shortly following the removal of blood, the blood pressure was frequently markedly depressed. The decline in pressure usually appeared much earlier in the experiments with the unexplained fall than in those in which blood was removed. It is possible that the vasoconstriction of the vessels which usually accompanies hemorrhage was responsible for the prevention of the loss of protein through the vessel walls in the present experiments, but we have no proof of this.

The addition of the protein that was removed to that remaining in the blood stream in the experiments on hemorrhage indicated an increase in the absolute amount of plasma protein in most of the experiments. Scott (5) from his studies on the mechanism of the absorption of fluid from the tissue spaces states: "The above results show that as large or larger increases in the nitrogenous bodies of the plasma occur after injecting 
Ringer's fluid (when all backward filtration is excluded) as occur after hemorrhage. After hemorrhage, the fluid passing back into the blood must contain less protein than the plasma whether it passes back by osmosis or by filtration, it will then necessarily cause protein to pass from the cells into the plasma. Consequently an increase of protein in the plasma after hemorrhage is no evidence of backward filtration and is consistent with Starling's view that the fluid passes into the capillaries by osmotic action." In previous experiments in which the effects of the injection of solutions of crystalloids into normal dogs were determined, there was a slight increase in the absolute amount of the plasma protein in several of the experiments but in most of them it remained at the same level or decreased slightly. However, in the present experiments in which both the effects of hemorrhages and the injection of fluids were studied, there was usually an increase in the plasma protein. If Scott is correct in his statement that backward filtration is excluded when fluid that has been injected is passing through the vessels, then it follows that protein did not pass from the tissue spaces into the blood stream in our experiments because part of the fluid that was injected escaped through the vessel walls. However, it is not necessarily true that backward filtration is excluded simply because part of the fluid that was injected was leaving the blood stream. It would seem to be possible that at any given time fluid could be leaving the blood stream in some areas while at the same time fluid could be passing into the circulation in other areas.

The experiments on the effects of trauma to an extremity differ in the main from those on hemorrhage in that the latter type was usually associated with a decrease in the concentration of the red blood cells, whereas a slight increase usually occurred in the former. The difference is probably due to the fact that there was a greater proportional loss of plasma than of red cells in the studies on trauma whereas hemorrhage resulted in the loss of blood as it existed at the time in the blood vessels. The above remarks do not apply to the experiments in which the gum acacia solution was injected, since in both types a marked decrease in the concentration of the red blood cells was found. The increase in the concentration of the blood in the experiments on the effects of trauma and the introduction of salt solution was not nearly so marked as in the previous experiments (2), in which the unexplained declines in pressure occurred. Also, the decrease in the percentage of protein in the blood serum in the present experiments was not nearly so great as in the former ones. Unfortunately the absolute amounts of the protein constituents could not be determined accurately during the course of the experiments on trauma. Since the fluid that escaped from the blood stream into the injured area had approximately the same composition as whole blood and since there was such a marked difference in the weight of the traumatized 
and non-traumatized parts, it is likely that most if not all of the protein was lost into the damaged tissues. The impression was gained that it took a greater amount of trauma to produce a decline in blood pressure when salt solution was injected than when no solutions were given. This observation would indicate that the salt solution was not exerting harmful effects.

Protein was usually lost from the blood stream when histamine and fluids were injected but it was surprising to us that the loss was not greater. The reduction in the percentage and absolute amount of plasma protein was usually not as great in these experiments as in the previous (2) ones with the unexplained decline in pressure. In the latter experiments the decline in pressure was frequently maintained for only a short while, whereas in the experiments on histamine the blood pressure was kept at a low level for a long time. At the completion of most of the experiments on histamine, the stomach contained large amounts of fluid. The content of this fluid in protein was quite low. It was sufficient to account for only a small part of the total loss of protein.

In the experiments on the effects of spinal anesthesia alone, there was either no loss in the absolute amount of plasma protein or the loss was not very great. When normal salt solution was introduced intravenously after producing a decline in pressure by spinal anesthesia, there was not a large loss of protein. The decline in the blood pressure in these experiments was similar to that observed in the experiments (2) in which the unexplained fall occurred. In both instances, a marked drop in the pressure was noted during the early part of the studies. It is possible that the absence of a large loss of protein in the experiments on spinal anesthesia was due to the fact that part rather than the whole of the body was affected by the anesthetic. In the experiments in which the unexplained decline in the pressure occurred and in those in which histamine was injected, the effects were probably general rather than local.

It is noted in some of the experiments reported in this paper that it is possible to have a marked decline in the blood pressure without an associated diminution in the absolute amount of plasma protein. This finding indicates that the unexplained decline in blood pressure in the experiments previously reported (2) was not entirely responsible for the loss.

\section{SUMMARY}

The effects on the composition of the blood of four different procedures which resulted in a decline in the blood pressure were determined in some dogs in which no fluid was injected and in others in which either normal salt solution or gum acacia-glucose-saline solution was introduced intravenously. The methods that were employed in reducing the blood pressure consisted of (1) the graded removal of blood, (2) trauma to an extremity, (3) the subcutaneous injection of histamine and (4) the injection 
of procaine hydrochloride into the spinal canal. The studies included determinations of the carotid blood pressure, the percentage of hemoglobin, the concentration of the red blood cells, the volumes of whole blood, red blood cells and plasma, and the percentages of total protein, albumin and globulin in the blood serum. The absolute amounts of the protein constituents were calculated by multiplying the percentage of each in the serum by the volume of plasma.

Some of the results that were obtained are as follows:

1. In the experiments on the effects of hemorrhage, both with and without the introduction of fluids, the amount of protein that was present in the blood that was removed was usually more than sufficient to account for the decrease in the total amount of protein in the plasma of the blood stream. The results of most of the experiments indicate that protein passed into the blood vessels.

2. In both the experiments on hemorrhage and those on trauma to an extremity, there was a slight decrease in the concentration of the plasma protein associated with the introduction of normal salt solution. The total amount of protein that was lost from the blood stream in the experiments on trauma could not be determined with accuracy but the results indicate that most if not all of it escaped into the injured area.

3 . In all of the experiments with one exception in which histamine was injected, there was a decrease in the absolute amounts of the protein constituents. However, the loss was not as great as was usually encountered in the previous experiments (2) in which the unexplained decline in blood pressure occurred.

4. There was a comparatively small loss of protein from the blood stream in the experiments in which a marked decline in the blood pressure followed the injection of procaine into the spinal canal. The findings were similar when in addition normal salt solution was introduced intravenously.

\section{BIBLIOGRAPHY}

1. Beard, J. W., and Blalock, Alfred, J. Clin. Invest., 1932, xi, 249. Intravenous Injections. Studies on the Composition of the Blood During Continuous Trauma to the Intestines When No Fluid is Injected and When Fluid is Injected Continuously.

2. Blalock, Alfred, Beard, J. W., and Thuss, Charles, J. Clin. Invest., 1932, xi, 267. Intravenous Injections. A Study of the Effects on the Composition of the Blood of the Injection of Various Fluids into Dogs with Normal and with Low Blood Pressures.

3. Cohen, B., and Smith, A. H., J. Biol. Chem., 1919, xxxix, 489. The Colorimetric Determination of Hemoglobin.

4. Blalock, Alfred, Arch. Surg., 1930, xx, 959. Experimental Shock. The Cause of the Low Blood Pressure Produced by Muscle Injury.

5. Scott, F. H., J. Physiol., 1915, 1, 157. The Mechanism of Fluid Absorption from Tissue Spaces. 